\title{
Formation of asperities on electrode surfaces of high-voltage vacuum insulation systems by striking microparticles
}

\author{
Arkadiusz Dobrzycki ${ }^{1,}{ }^{*}$ Władysław Opydo ${ }^{2}$, Kazimierz Bieliński ${ }^{2}$, Grzegorz Twardosz ${ }^{1}$ \\ ${ }^{1}$ Poznan University of Technology, Faculty of Electrical Engineering, Piotrowo 3A, 60-965 Poznan, Poland \\ ${ }^{2}$ UTP University of Science and Technology, Faculty of Telecommunications, Computer Science and Electrical Engineering, , Al. prof. \\ S. Kaliskiego 7, 85-796 Bydgoszcz, Poland;
}

\begin{abstract}
The authors analyzed the ability to produce asperities on the surface of discharge electrodes vacuum insulation systems by hitting the electrode surface small clumps of material - microparticles. Insulation systems with electrodes made of copper, aluminum and titanium were analyzed. The dependence on the distance between the electrodes and the minimum voltage value at the terminals of the insulation system was determined, under the influence of which accelerated spherical microparticles with different radii cause deformations of the electrode surface.
\end{abstract}

\section{Introduction}

State analysis, design optimization, and life prediction of electrical equipment are important operational issues [13]. In case of high voltage insulation systems in analyzes often complex computational algorithms are used [4-6]. In investigations of the properties of vacuum insulation systems, the authors indicate that if the voltage exceeds a certain level, irreversible changes occur in the system [7]. Because their effect is a rapid increase in the value of the field emission electron emission, these changes consist in the formation of microedges with a high amplification factor of the electric field on the surface of the electrodes. From physical phenomena occurring in vacuum insulation systems, the reason for such sudden creation of a microedge may be the impact on the surface of the electrode of the metallic microparticle causing creation the asperity [8].

This paper presents an analysis of the possibility of producing such asperities. It has been assumed that the striking microparticles have the shape of a sphere and are made of the same metal as the electrode in which they strike. The systems with electrodes made of copper, aluminum, [8] and titanium [9] were analyzed.

\section{Calculation method}

The speed of a spherical microparticle at the moment of impact on the surface of the opposite electrode depends on the voltage applied, the distance between the electrode and the material of the microparticle [10].

For a striking microparticle to cause plastic deformation of the electrode material, it must have a speed greater than the critical deformation rate of the plastic material of the electrode, defined as the smallest value of the speed that must be given to a part of the material to cause plastic deformation. Critical velocity of plastic strain $v_{\mathrm{p}}$ expresses the formula [8]

$$
\vartheta_{p}=\left(\frac{8 R_{e}}{\delta_{e}}\right)^{1 / 2}
$$

where: $\mathrm{R}_{\mathrm{e}}-$ yield stress of the electrode material, $\delta_{\mathrm{e}}-$ density of the electrode material.

Assuming that the spherical microparticle is made of the same material as the electrode in which it strikes, the minimum voltage applied to the terminals of the insulating system, which will cause the microparticle on impact will cause deformation of the electrode surface is

$$
U=\left(\frac{8 R_{e} r_{m} d}{\pi^{2} \varepsilon_{0}}\right)^{1 / 2}
$$

where: $r_{\mathrm{m}}-$ microparticle radius, $\mathrm{d}$ - distance between electrodes, $\varepsilon_{0}-$ vacuum permittivity.

\section{Calculation results}

From the formula (2) were determined the dependences of the minimum value of voltage applied to the vacuum insulation system, causing the spherical microparticle acceleration in the inter-electrode space to the speed necessary to plastic deform the surface of the electrode in which it hits, to the radius of the microparticle.

Dependencies were determined for insulation systems with electrodes made of copper, aluminum and titanium, with inter-electrode spacing of 1,5 and $10 \mathrm{~mm}$. The following values of yield strength of electrode materials were used in the calculations: copper $\mathrm{ReCu}=$ $35 \mathrm{MPa}$, aluminum $\mathrm{ReAl}=60 \mathrm{MPa}$ and titanium $\mathrm{ReTi}=$ $170 \mathrm{MPa}$. These dependencies are shown in Fig. 1. 
Whereas, Fig. 2 shows the dependence of the minimum voltage applied to the vacuum insulation system, determined from formula (2), causing acceleration the spherical microparticle to the velocity effects the plastic deformation of the electrode surface to which it strikes, from the length of the gap between electrodes in insulation system.

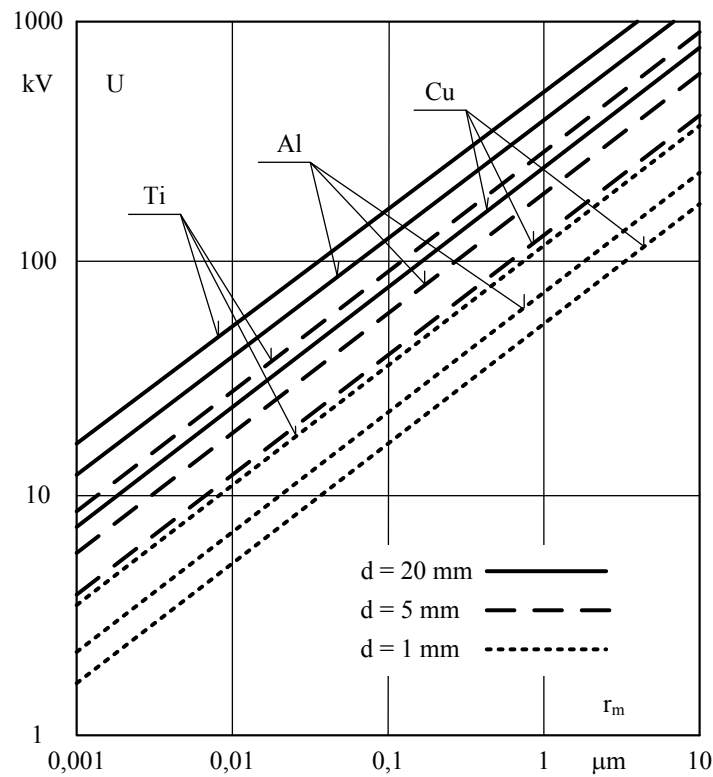

Fig. 1. The dependence of the minimum voltage value that causes the spherical microparticle to accelerate to the velocity causing the plastic deformation of the electrode surface in which it strikes from the radius of the microparticle; the interelectrode spacing $\mathrm{d}$ was 1,5 and $20 \mathrm{~mm}$, and the electrodes and striking microparticles were made of $\mathrm{Cu}, \mathrm{Al}$ or Ti.

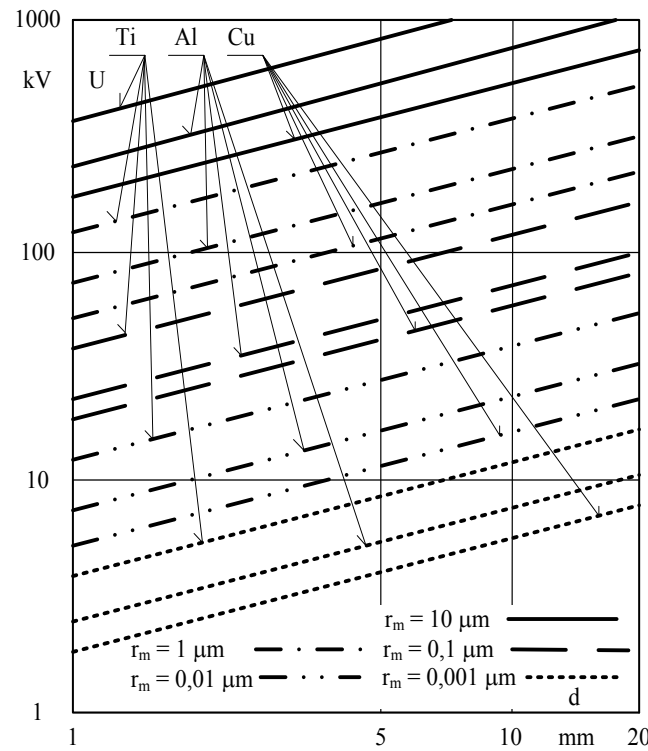

Fig. 2. Dependence of the minimum voltage value, causing in the insulation systems with electrodes made of $\mathrm{Cu}, \mathrm{Al}$ or $\mathrm{Ti}$, acceleration of spherical microparticles, with a radius $\mathrm{r}_{\mathrm{m}}$ equal to $0.001,0.01,0.1,1$ and $10 \mu \mathrm{m}$, to the velocity causing plastic deformation of the electrode surface in which they hit, from the length of the electrode gap.

Different values of yield points of electrode materials cause that in the relations shown in Fig. 1 and Fig. 2, the minimum voltage causing acceleration of the microparticle to the velocity causing plastic deformation of the electrode surface is the smallest when electrodes are made from copper, slightly higher in the case of aluminum electrodes and the largest for systems with titanium electrodes.

From Fig. 1 and Fig. 2 it also follows that in the case of vacuum insulation systems, with $1 \mathrm{~mm}$ and with a 5 $\mathrm{mm}$ distance between electrodes, at voltages slightly lower than given above values of electrical strength, microparticles with radii up to several tenths of micrometer can cause deformation of the surface of the electrodes in which they strike. It seems that the height of the asperity produced by the microparticle is close to its radius. With this assumption follows, from Fig. 1 and Fig. 2, that at voltage values slightly lower than the electrical strength values of the systems (given above), the strikingly inconsistent surfaces of the microparticles have a radius of tenths of a micrometer. It can therefore be assumed that the asperities size they created were of the same order of magnitude.

\section{References}

1. A. Dobrzycki, A. Knitter-Piątkowska, ITM Web of

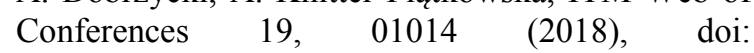
https://doi.org/10.1051/itmconf/20181901014

2. L. Kasprzyk, Prz. Elektrotechniczny, 88, 7B, (2012)

3. D. Kurz, L. Morawska, R. Piechota, G. Trzmiel, E3S Web of Conferences, 44, 00085, (2018) https://doi.org/10.1051/e3sconf/20184400085

4. A. Dobrzycki, S. Mikulski, W. Opydo, Appl. Sci. $2019,9,1523$

5. A. Dobrzycki, W. Opydo and S. Zakrzewski, 2018 IEEE International Conference on High Voltage Engineering and Application (ICHVE), ATHENS, Greece, 2018, pp. 1-4. doi: 10.1109/ICHVE.2018.8642212

6. W. Opydo, A. Dobrzycki, Electr. Eng.94, 37 (2012) https://doi.org/10.1007/s00202-011-0219-1

7. M. M. Menon, K. D. Srivastava, Proc. VI International Symposium on Discharges and Electrical Insulation in Vacuum, Svansea, 1974, p. 3

8. Opydo W., Ranachowski J., Właściwości elektryczne próżniowych układów izolacyjnych przy napięciu przemiennym, (PWN, Warszawa - Poznań 1993)

9. Erven C. C., Wavre J. J., van Heeswijk R. G., Proc. IV International Symposium on Discharges and Electrical Insulation in Vacuum, Waterloo, Canada, 1970, s. 219

10. A. Dobrzycki, W. Opydo, G. Twardosz, K. Bieliński, Academic Journals Poznan University of Technology, 2019, 98, DOI 10.21008/j.18970737.2019.98.0018

11. M. A. Cook, The science of high explosives, (Reinhold Publications, New York 1958) 